\title{
Ameliorating effects of chicken feathers in plant growth promotion activity by a keratinolytic strain of Bacillus subtilis PF1
}

\author{
Khushboo Bhange ${ }^{1}$, Venkatesh Chaturvedi ${ }^{2}$ and Renu Bhatt ${ }^{1 *}$
}

\begin{abstract}
Background: Feathers are the major byproducts of poultry industry and considered as waste. Feathers (composed of protein keratin) are metabolized by a number of microorganisms as a source of carbon and nitrogen. Degradation of feathers results in production of amino acids and peptides, which can be employed as precursors for plant growthpromoting metabolites such as indole acetic acid, ammonia and HCN. The aim of the present investigation was to assess the influence of these metabolites (termed as feather protein hydrolysate) on plant growth promotion activity of keratinolytic bacterial strain Bacillus subtilis PF1.
\end{abstract}

Results: Strain PF1 exhibits potent keratinolytic activity and can efficiently degrade $10 \mathrm{~g} / \mathrm{l}$ chicken feathers under submerged cultivation with $81.4 \pm 4.40 \mathrm{U} / \mathrm{ml}$ keratinase activity. Different concentrations of feathers supported the production of indole acetic acid by strain PF1. Strain PF1 produces maximum indole acetic acid ( $46.2 \pm 0.21 \mu \mathrm{g} / \mathrm{ml})$ in the presence of $2.0 \%$ feathers at $120 \mathrm{~h}$ of incubation. The indole acetic acid production was confirmed by thin-layer chromatography and Fourier transform infrared spectroscopic analysis. However, increased concentration of feathers exhibited negative effect on phosphate solubilization due to increased alkalinity. HCN production also exhibited positive correlation with concentration of feathers. Finally, plant growth of Vigna radiata in the presence of strain PF1 with chicken feathers in soil was investigated, which showed good plant growth promotion activity. Increased ratio of C/N in soil also supported the plant growth promotion activity of feathers.

Conclusion: Feather degradation property of B. subtilis PF1 could be efficiently utilized for feather waste management. The metabolites released by feather degradation along with strain PF1 could be successfully employed as an economic source of nitrogen fertilizers for plants.

Keywords: Bacillus subtilis PF1, Chicken feather, Indole acetic acid production, Phosphate solubilization, HCN production

\section{Background}

Maintenance of high agriculture productivity is a prerequisite to cater the demands of growing population (Perez-Montano et al. 2014). To increase the productivity of crops, synthetic fertilizers are being used all over the world. Overuse of these fertilizers leads to their gradual entry into water systems through rain water and causes eutrophication. Recently, several biological approaches

\footnotetext{
*Correspondence: dr.renubhatt@yahoo.com

${ }^{1}$ Department of Biotechnology, Guru Ghasidas Vishwavidyalaya (A

Central University), Bilaspur 495009, Chhattisgarh, India

Full list of author information is available at the end of the article
}

for improving crop productivity are gaining strong impetus among agronomists and environmentalists. Among these approaches, the use of plant growth-promoting (PGP) bacteria is believed as the most competent and economical system for escalating the yield of various crops (Ahemad and Kibret 2014). Various microorganisms such as the Bacillus, Pseudomonas and Trichoderma have been considered as potential plant growth-promoting factors and augment crop production under field conditions (Verma et al. 2013). Various plant growthpromoting factors such as indole acetic acid (IAA), phosphate solubilization and nitrogen fixation, and
Springer Open

(c) 2016 Bhange et al. This article is distributed under the terms of the Creative Commons Attribution 4.0 International License (http://creativecommons.org/licenses/by/4.0/), which permits unrestricted use, distribution, and reproduction in any medium, provided you give appropriate credit to the original author(s) and the source, provide a link to the Creative Commons license, and indicate if changes were made. 
bio-control attributes like production of $\mathrm{HCN}$, siderophore, hydrolytic enzymes and antibiotics have been previously reported for Bacillus sp. (Senthilkumar et al. 2009, Kumar et al. 2012, Sunar et al. 2013).

Chicken feathers are keratin-rich waste generated in large amount from poultry processing industries. High mechanical stability and rigid nature of keratin make them resistant to degradation by common proteolytic enzymes present in nature (Lateef et al. 2010). Release of large amount of chicken feathers from poultry processing industries causes their accumulation (Tatineni et al. 2008). Inappropriate disposal of these wastes by the methods such as dumping, land filling and incineration not only leads to environmental havoc but is also responsible for loss of useful biological resources such as protein, enzymes, etc. (Lasekan et al. 2013). Preparation of biofertilizers using chicken feather wastes is attracting the focus of many research scientists. Feather meal is a cheap and easily available source of nitrogen $(15 \% \mathrm{~N})$ and may serve as a potential biofertilizer (Jeong et al. 2010a). The plant growth-promoting activity of protein hydrolysates could also be effectively applied in agriculture (Tiwary and Gupta 2010). Thus, microbial degradation of feather represents an alternative for development of slow-release nitrogen fertilizers. Indole-3-acetic acid (IAA) is a major plant growth regulator which increases the accessibility of nutrients to plant and also promotes root growth (Vessey 2003). The degraded product of chicken feathers could generate appropriate amount of tryptophan which is the key source of IAA synthesis (Tsavkelova et al. 2012). Indole acetic acid-producing and phosphate-solubilizing bacteria are capable of stimulating plant growth (Das and Tiwary 2014).

The present study deals with the study of plant growthpromoting attributes of keratinolytic bacterial strain Bacillus subtilis PF1. A comparison of plant growthpromoting factors, namely IAA, ammonia, phosphate solubilization and $\mathrm{HCN}$ production, was quantitatively performed in the presence and absence of chicken feathers, aiming to evaluate any positive and negative role of feather metabolism in these attributes. Further, Mung bean (Vigna radiata) is an important pulse crop belonging to the family Fabaceae and chiefly grown for its edible seeds rich in protein. It also contributes to a good source of essential fatty acids, tocopherols, sterols, sugars, organic acids, amino acids and amines (Silva et al. 2013). Therefore, the role of keratinolytic strain B. subtilis PF1 for growth of $V$. radiata during feather degradation was also determined.

\section{Methods}

\section{Microorganism and culture condition}

A potential keratinolytic strain B. subtilis PF1 (accession no. KM062030) isolated from feather disposal site of Bilaspur, Chhattisgarh, India, was used in the present investigation. The strain was grown on feather meal broth (FMB) consisted of the following ( $\mathrm{g} / \mathrm{l}): \mathrm{K}_{2} \mathrm{HPO}_{4}, 0.3$; $\mathrm{KH}_{2} \mathrm{PO}_{4}, 0.4 ; \mathrm{NaCl}, 0.5$; feathers, 10. Peptone water was used for inoculum preparation, which was consisted of the following (g/l): peptone, 10.0 and $\mathrm{NaCl}, 5.0 .5 \%(\mathrm{w} / \mathrm{v})$ of 24-h-old culture of bacterial strain was transferred in 500-ml Erlenmeyer flasks containing $250 \mathrm{ml}$ FMB. The flasks were incubated in a shaking incubator (Remi CIS$24 \mathrm{BL}$, India) at $150 \mathrm{rpm}$ and $32^{\circ} \mathrm{C}$. Feathers used in the study were obtained from a regional poultry farm, Bilaspur, Chhattisgarh, India. They were washed thoroughly with detergent followed by water for 2-3 times to remove dust and blood stains and then were dried in hot air oven for $24 \mathrm{~h}$ at $60^{\circ} \mathrm{C}$. The chemicals used in this study were of pure analytical grade and purchased from Sigma chemicals and HiMedia, India.

\section{Time course study of feather degradation in basal feather medium}

Initially, strain PF1 was inoculated in peptone water and incubated for $24 \mathrm{~h}$ at $150 \mathrm{rpm}$ and $32^{\circ} \mathrm{C}$. In 500-ml Erlenmeyer flasks containing $250 \mathrm{ml}$ minimal medium supplemented with $1 \%(\mathrm{w} / \mathrm{v})$ chicken feathers, $5 \%$ inoculums were transferred. The flasks were incubated for $24 \mathrm{~h}$ at $150 \mathrm{rpm}$ and $32{ }^{\circ} \mathrm{C}$. Aliquots of $2 \mathrm{ml}$ were withdrawn after every $24 \mathrm{~h}$ from each triplicate culture to evaluate growth, keratinase activity, soluble protein and amino acid production. Estimation was performed from culture supernatant obtained by centrifugation of culture at $12,000 \mathrm{rpm}$ for $10 \mathrm{~min}$.

Growth rate was determined by tetrazolium chloride (TTC) reduction method as described by De Logu et al. (2001). Briefly, $10 \mu \mathrm{l}$ of $0.02 \%$ TTC solution was added to $1 \mathrm{ml}$ culture suspension and incubated at $30{ }^{\circ} \mathrm{C}$ for $30 \mathrm{~min}$, and the cell suspension was then subjected to centrifugation at $8000 \mathrm{rpm}$ for $10 \mathrm{~min}$. The cell pellet was treated with $95 \%$ ethanol, incubated for another $30 \mathrm{~min}$ and again centrifuged at $8000 \mathrm{rpm}$ for $10 \mathrm{~min}$. The absorbance of supernatant was recorded at $480 \mathrm{~nm}$.

Keratinase assay was performed according to the method of Anbu et al. (2007) with minor modifications. Twenty $\mathrm{mg}(20 \mathrm{mg})$ of chopped feathers were suspended in $3.8 \mathrm{ml}$ of $100 \mathrm{mM}$ Tris-HCl buffer (pH 8.0) followed by addition of $200 \mu \mathrm{l}$ of culture supernatant to it. This preparation was incubated at $32{ }^{\circ} \mathrm{C}$ and $150 \mathrm{rpm}$ for $1 \mathrm{~h}$ and the reaction was stopped by cooling the tubes in ice-chilled water. After centrifugation at $5000 \mathrm{rpm}$ for $5 \mathrm{~min}$, the absorbance of supernatant was measured at $280 \mathrm{~nm}$. Control samples were prepared in a similar manner except that the enzyme was replaced by the same volume of $100 \mathrm{mM}$ Tris- $\mathrm{HCl}$ buffer (pH 8.0). One unit of enzyme activity was considered as the amount of enzyme 
required to release $1 \mu \mathrm{mol} / \mathrm{min}$ of tyrosine under the conditions mentioned above. Similar experiments were performed for measuring protease activity using casein as a substrate. The other parameters were followed same as keratinase assay.

Bradford method (1976) was used to determine protein concentration and bovine serum albumin (BSA) as standard. The absorbance was determined spectrophotometrically at $590 \mathrm{~nm}$ using UV-Vis spectrophotometer (UV-1800, Shimadzu). Total amino acid content was measured by manual ninhydrin method using leucine as standard (Cheng et al. 2010).

\section{Study of IAA and ammonia production}

The bacterial strain was cultured in the presence and absence of different concentrations of tryptophan, and the production of IAA was estimated spectrophotometrically at $530 \mathrm{~nm}$. Minimal media containing $1 \%(\mathrm{w} / \mathrm{v})$ of chicken feathers and different concentrations of tryptophan $(0.02-0.2 \mathrm{mM})$ were inoculated with bacterial culture suspension and incubated at $32^{\circ} \mathrm{C}$ and $150 \mathrm{rpm}$. Aliquots of $2 \mathrm{ml}$ were retrieved from each triplicate culture after every $24 \mathrm{~h}$ to determine the concentration of IAA. The supernatant $(1 \mathrm{ml})$ of grown culture was mixed with $500 \mu$ of Salkowski reagent $\left(2 \%\right.$ of $0.5 \mathrm{M} \mathrm{FeCl}_{3}$ in $35 \%$ perchloric acid) and the concentration of IAA was estimated after $20 \mathrm{~min}$ by measuring the absorbance at $530 \mathrm{~nm}$ (Jeong et al. 2010a). The absorbance was compared with standard prepared by using IAA (HiMedia, India). The influence of different feather concentrations $(0.25-2.0 \% \mathrm{w} / \mathrm{v})$ along with $0.5 \mathrm{mM}$ tryptophan in culture medium was also estimated over the production of indole acetic acid. Minimal medium containing $0.5 \mathrm{mM}$ tryptophan was considered as control.

Thin-layer chromatography (TLC) and Fourier transform infrared spectroscopy (FTIR) were utilized to analyse IAA production (Sachdev et al. 2009) using commercial IAA (Himedia, India) as standard. For acidic extraction, 72-h-grown culture supernatant of feather lysate was adjusted to $\mathrm{pH} 2$ with $0.1 \mathrm{~N} \mathrm{HCl}$ and subsequently extracted with equal volume of ethyl acetate. The ethyl acetate fraction was concentrated in a vacuum evaporator (Concentrator plus, Eppendorf), mixed with $\mathrm{KBr}$ and analysed using FTIR (FTIR 8400, Shimadzu). Infrared spectrum of IAA was recorded and expressed in wave numbers $\left(\mathrm{cm}^{-1}\right)$.

Ammonia production was determined according to the method of Goswami et al. (2014). Briefly, the strain PF1 was grown on $10 \mathrm{ml}$ minimal media containing different concentrations of chicken feathers $(0.25-2.0 \%)$ and incubated at $32{ }^{\circ} \mathrm{C}$ for $72 \mathrm{~h}$. Afterwards, the culture was centrifuged at $10,000 \mathrm{rpm}$ for $10 \mathrm{~min}$ to obtain culture supernatant. Subsequently, $0.1 \mathrm{ml}$ of Nessler's reagent was added in the test tube containing $1 \mathrm{ml}$ culture supernatant and the volume of this mixture was made up to $5 \mathrm{ml}$ by the addition of ammonia-free double-distilled water. OD was measured at $450 \mathrm{~nm}$. The concentration of ammonia was estimated to be in the range of $0.1-1.0 \mu \mathrm{g} /$ $\mathrm{ml}$ using standard curve of ammonium sulphate.

\section{Phosphate solubilization activity of bacterial strain and influence of feather on phosphate solubilization}

The phosphate solubilization by the strain PF1 was determined qualitatively according to the method described by Mehta and Nautiyal (2001). The bacterial strain PF1 was grown in the NBRI-BPB medium composed of $(\mathrm{g} / \mathrm{l})$ the following: sucrose, $10.0 ; \mathrm{Ca}_{3}\left(\mathrm{PO}_{4}\right)_{2}, 5.0 ; \mathrm{MgCl}_{2} \cdot 6 \mathrm{H}_{2} \mathrm{O}, 5.0$; $\mathrm{MgSO}_{4} \cdot 7 \mathrm{H}_{2} \mathrm{O}, 0.25$; $\left(\mathrm{NH}_{4}\right) \mathrm{SO}_{4}, 0.1$; bromophenol blue, 0.025 . The $\mathrm{pH}$ of the culture medium was adjusted to 7.0 prior to sterilization (Mehta and Nautiyal 2001). The bacterial culture was inoculated in NBRI-BPB agar medium and kept for incubation at $32{ }^{\circ} \mathrm{C}$ for $24 \mathrm{~h}$. The plates were observed for the formation of halos around the inoculated culture. The effect of different concentrations of feather on phosphate solubilization was estimated quantitatively by Mo-blue method (Olsen et al. 1982). Briefly, 30-ml test tube containing $10 \mathrm{ml} \mathrm{NBRI-BPB}$ medium and different concentrations of sterilized feather lysate $(0.25-$ $2.0 \%$ ) were inoculated with $1 \mathrm{ml}$ of bacterial suspension and incubated at $32{ }^{\circ} \mathrm{C}$ for 3 days in a shaking incubator at $120 \mathrm{rpm}$. The cultures were centrifuged at 10,000 rpm for $10 \mathrm{~min}$, and soluble phosphate in culture supernatant was estimated at $882 \mathrm{~nm}$ using UV-Vis spectrophotometer (Das and Tiwary 2014).

\section{$\mathrm{HCN}$ production}

For the qualitative estimation of $\mathrm{HCN}$ production by strain PF1, picrate assay was performed as described by Castric (1974). Strain PF1 was streaked on LB medium supplemented with $4.4 \mathrm{~g} \%$ glycin. A Whatman filter paper No. 1 (soaked in solution of $2 \% \mathrm{Na}_{2} \mathrm{CO}_{3}$ in $0.5 \%$ picric acid) was placed in between base and lid of the culture plate. Plates were sealed with parafilm and incubated at $32{ }^{\circ} \mathrm{C}$ for $96 \mathrm{~h}$. Production of $\mathrm{HCN}$ was indicated by colour changes on filter paper from yellow to orange brown (Goswami et al. 2014). For quantitative estimation of $\mathrm{HCN}$ in different concentrations of feather, the strain PF1 was grown in FMB containing different concentrations of chicken feathers $(0.25-2.0 \%)$ and $4.4 \mathrm{~g} \%$ glycin. After $96 \mathrm{~h}$ of incubation, the $2 \mathrm{ml}$ culture was treated with $1 \mathrm{ml}$ picrate solution (solution of $2 \% \mathrm{Na}_{2} \mathrm{CO}_{3}$ in $0.5 \%$ picric acid) and kept at $30{ }^{\circ} \mathrm{C}$ for $24 \mathrm{~h}$. After that, all the cultures were centrifuged at 10,000 rpm for $5 \mathrm{~min}$. The absorbance of supernatant was read at $625 \mathrm{~nm}$ (Sadasivam and Mannikkam 1992). Increasing absorption at $625 \mathrm{~nm}$ was considered as an increase in $\mathrm{HCN}$ production. 


\section{Plant growth promotion study}

Certified seeds of $V$. radiata released by the Department of Food and Agriculture, Government of Chhattisgarh, India, were used in this study. The seeds of $V$. radiata were surface sterilized with $2 \%$ mercuric chloride for $20 \mathrm{~min}$ and were washed thrice with sterilized doubledistilled water. Twelve seeds (four seeds in each sterile tissue culture tube) were placed in sterilized soil containing water only (control S1), water and $10^{8}$ bacterial cells $\mathrm{ml}^{-1}$ (S2), and sterilized feathers with bacterial suspension containing induced $10^{8}$ bacterial cells $\mathrm{ml}^{-1}$ (S3). Bacterial cells were previously grown in $1.0 \%$ feathercontaining minimal media. After a week of incubation, the germination percentage of the seeds and radicle and plumule length were determined.

\section{Chemical analysis of soil samples}

Three sets of pot soil were used for chemical analysis, namely untreated or control (devoid of bacterial suspension and feathers), soil treated with bacterial suspension and soil treated with both bacterial suspension and feathers. The samples were collected after 10 days of incubation for physiochemical analysis. The suspension of soil samples was prepared in distilled water $(1: 3 \mathrm{w} / \mathrm{v})$ and $\mathrm{pH}$ was measured. For the determination of total nitrogen content, Kjeldahl method (Eaton et al. 1995) was used and total carbon content was estimated by Tyurin method (Nustorova et al. 2006). The contents of P, K, Na, $\mathrm{Ca}$ and $\mathrm{Mg}$ were determined by atomic absorption spectroscopy (Shimadzu, AA-6200).

\section{Statistical analysis}

All the experiments were performed in triplicate and the results were represented as mean \pm standard deviation. The results were compared by one-way ANOVA followed by Tukey-Kramer comparison test.

\section{Results}

\section{Time course of feather degradation}

The time course of feather degradation by strain PF1 was determined during submerged cultivation in minimal medium containing $1 \%(\mathrm{w} / \mathrm{v})$ feathers. Growth profile of strain PF1 indicated that the selected strain efficiently utilized chicken feathers as a sole source of carbon and nitrogen and attained highest growth at the 5 th day of incubation (Fig. 1a). Maximum soluble protein $(533.76 \pm 6.6 \mu \mathrm{g} / \mathrm{ml})$ production was observed at the 5 th day of cultivation or late exponential phase of growth (Fig. 1b). The time course of amino acid production exhibited similar pattern as keratinase (Fig. 1b). However, the maximum production of keratinase $(81.4 \pm 4.4$ $\mathrm{U} / \mathrm{ml})$ and protease $(172.7 \pm 2.8)$ was obtained at midlog phase of growth (Fig. 1c). The increased production
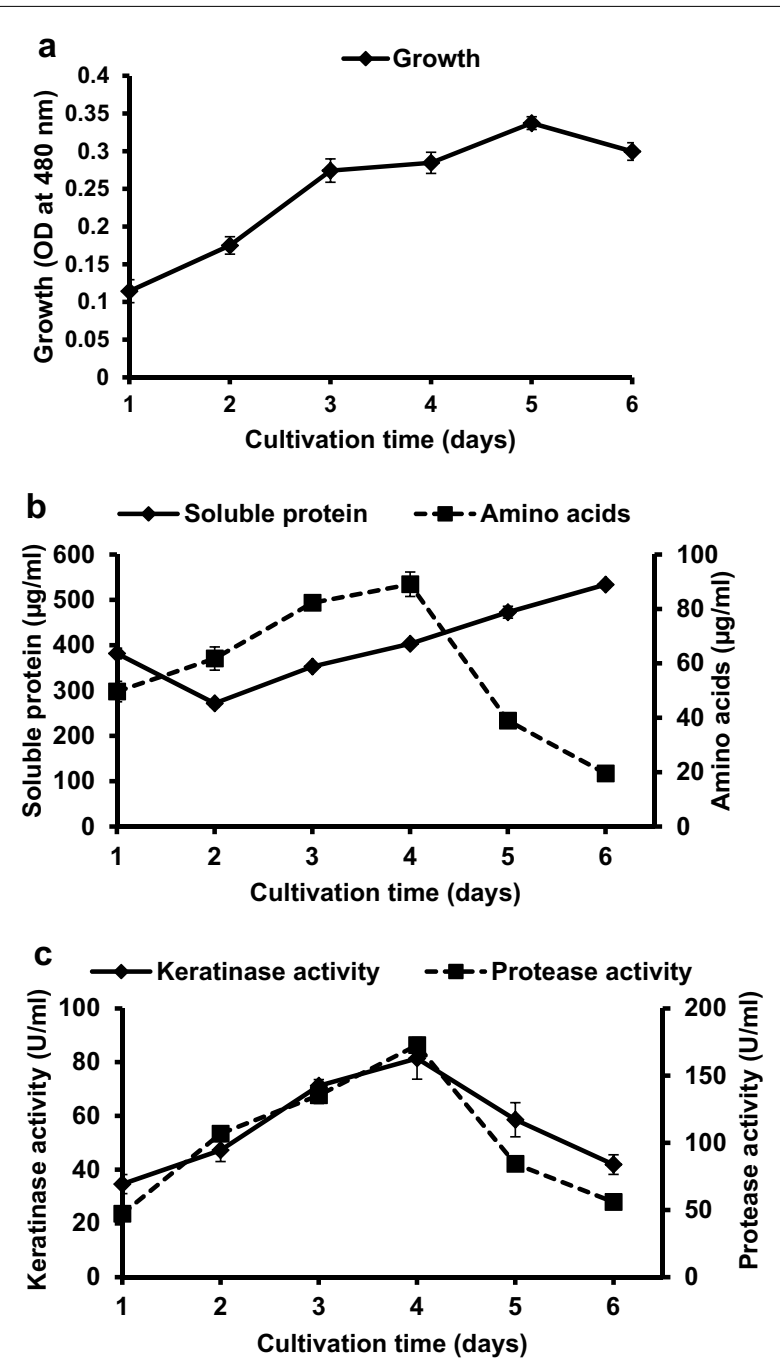

Fig. 1 Time course study of growth and feather degradation by Bacillus subtilis PF1 on FMB supplemented with $1 \%(\mathrm{w} / \mathrm{v})$ chicken feathers, incubated at $150 \mathrm{rpm}$ and $32^{\circ} \mathrm{C}$. Time course study of $\mathbf{a}$ growth, b soluble protein and amino acid production and $\mathbf{c}$ protease and keratinase production. The result is represented as mean \pm standard deviation of three independent variables

of keratinase leads to the increased production of amino acids during feather degradation.

\section{Production of IAA}

The production of IAA was evaluated during submerged cultivation in the presence and absence of L-tryptophan in feather meal broth. The result indicated increased production of IAA with increasing concentration of L-tryptophan from 0.02 to $0.2 \%$ (Fig. 2a). However, the time course study of IAA production reveals its maximum production $145.3 \pm 6.6 \mu \mathrm{g} / \mathrm{ml}$ at the 3rd day of incubation with $0.2 \%(\mathrm{w} / \mathrm{v})$ tryptophan. Table 1 shows the time course study of the effect of different concentrations of 

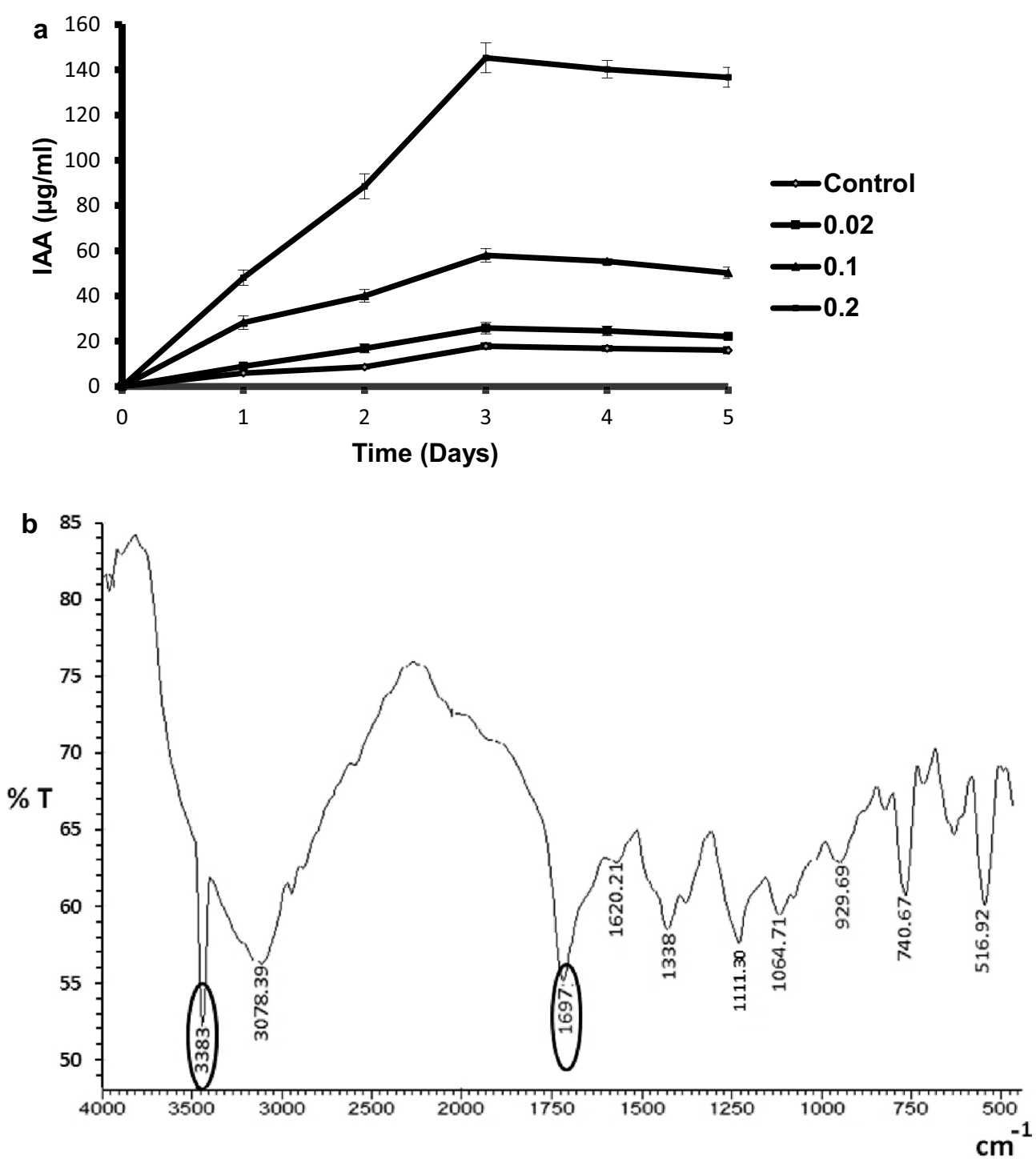

Fig. 2 a Time course of IAA production by Bacillus subtilis PF1 in the presence of various concentrations of L-tryptophan. The result is represented as mean \pm standard deviation of three independent variables. b The IR spectrum of the purified compound showed OH frequency at $3383.2 \mathrm{~cm}^{-1}$ and $\mathrm{C}=\mathrm{O}$ frequency at $1697.3 \mathrm{~cm}^{-1}$ similar to the IR spectrum of standard IAA

Table 1 IAA production $(\mu \mathrm{g} / \mathrm{ml})$ at different concentrations of chicken feathers by the strain PF1

\begin{tabular}{lrlrrrrr}
\hline Hours & \multicolumn{1}{c}{ Control } & \multicolumn{1}{l}{$\mathbf{0 . 2 5} \%$} & \multicolumn{1}{c}{$\mathbf{0 . 5 0} \%$} & $\mathbf{0 . 7 5} \%$ & $\mathbf{1 . 0} \%$ & $\mathbf{1 . 5} \%$ & $\mathbf{2 . 0} \%$ \\
\hline 24 & $8.9 \pm 0.7$ & $2.77 \pm 0.06$ & $4.75 \pm 0.37$ & $6.87 \pm 0.66$ & $12.64 \pm 1.21^{*}$ & $14.56 \pm 1.39^{*}$ & $16.05 \pm 2.62^{*}$ \\
48 & $16.8 \pm 1.9$ & $3.33 \pm 0.39$ & $7.20 \pm 0.55$ & $9.19 \pm 0.73$ & $17.5 \pm 1.17$ & $27.51 \pm 1.28^{*}$ & $28.96 \pm 2.98^{*}$ \\
72 & $25.76 \pm 2.4$ & $3.90 \pm 0.15$ & $10.26 \pm 0.21$ & $11.85 \pm 0.57$ & $22.44 \pm 0.96$ & $38.50 \pm 2.09^{*}$ & $40.08 \pm 3.2^{*}$ \\
96 & $24.6 \pm 2.0$ & $4.30 \pm 0.55$ & $12.73 \pm 0.45$ & $16.46 \pm 0.57$ & $27.00 \pm 0.84$ & $43.25 \pm 2.21^{*}$ & $43.98 \pm 2.14^{*}$ \\
120 & $22.1 \pm 1.4$ & $5.46 \pm 0.47$ & $15.09 \pm 0.80$ & $19.94 \pm 0.78$ & $33.66 \pm 1.0^{*}$ & $45.37 \pm 2.11^{*}$ & $46.2 \pm 0.21 *$ \\
\hline
\end{tabular}

The experiments were performed in triplicate and individual values are depicted as mean \pm standard deviation

* Denotes a value significantly greater than the control value $(p<0.05)$ 
chicken feathers $(0.25-2.0 \%)$ over the production of IAA. The IAA production showed linearity with increasing concentration of chicken feathers as compared to control. Strain PF1 produces maximum IAA $(46.2 \pm 0.21 \mu \mathrm{g} /$ $\mathrm{ml}$ ) in the presence of $2.0 \% \mathrm{FPH}$ at $120 \mathrm{~h}$ of incubation. This result suggested the ability of strain PF1 to synthesize IAA in the presence of feather-degraded metabolites. It has been reported that feather-degraded metabolites contain essential amino acid tryptophan in significant concentration required for the production of IAA (Jeong et al. 2010a). Production of IAA was also estimated by TLC method. The Rf value close to commercial IAA confirmed the presence of IAA (unpublished data). Sample contains IAA band retrieved by TLC and analysed with FTIR analysis. The IR spectrum of the purified compound showed the stretching of $\mathrm{OH}$ and $\mathrm{C}=\mathrm{O}$ at 3383.2 and $1697.3 \mathrm{~cm}^{-1}$, respectively, which is similar to the IR spectrum of standard IAA (Fig. 2b).

\section{Estimation of ammonia production}

Ammonia production by the strain was confirmed by reddish brown colour in overnight-grown culture of strain PF1 in peptone water after the addition of Nessler's reagent as compared to control (Fig. 3A). Influence of different concentrations of feather was also evaluated

\section{A}

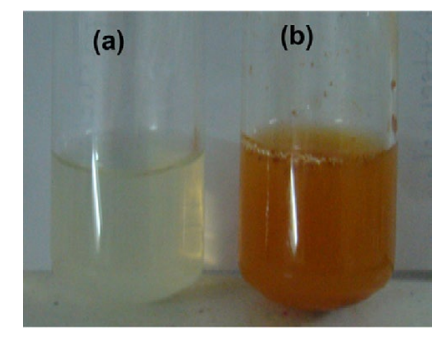

B

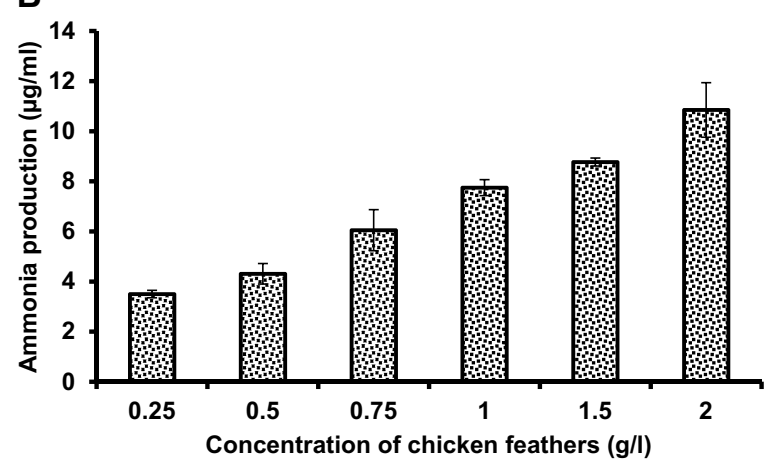

Fig. 3 A Visual observation of ammonia production by strain PF1 (a) and control (b) test. B Production of ammonia by Bacillus subtilis PF1 in the presence of different concentrations of feathers. The result is represented as mean \pm standard deviation of three independent variables for the production of ammonia. It was observed that the production of ammonia was gradually increased by the feather concentration of the media. Maximum production of ammonia $(10.85 \mu \mathrm{g} / \mathrm{ml})$ was estimated in the presence of $2.0 \%$ chicken feathers (Fig. 3B).

\section{Estimation of phosphate solubilization}

Phosphate solubilization was performed in NBRI-BPB agar media and broth. Decolourization of NBRI-BPB media and broth by strain PF1 indicated that the strain was capable of phosphate solubilization. However, a significant decrease in phosphate solubilization was observed as the concentration of feather was increased. Phosphate solubilization was not supported by strain PF1 after the concentration of $1 \%$ feather (Fig. 4).

\section{HCN production}

Minimal changes in colour of filter paper (soaked in $2 \%$ sodium carbonate prepared in $0.05 \%$ picric acid) from yellow to light orange indicated weak $\mathrm{HCN}$ production by strain PF1. Increasing concentration of feather in culture medium with the addition of $4.4 \mathrm{~g} / \mathrm{l}$ glycine positively influences the $\mathrm{HCN}$ production by strain PF1. Maximum production of cyanide was observed in the presence of $2 \%$ of chicken feather (Fig. 5).

\section{Effect of degraded metabolites on plant growth promotion} Effect of supplementation of feathers on germination and growth of $V$. radiata was studied after 7 days on incubation (Table 2). Figure 6 clearly indicates the increased growth of $V$. radiata in the presence of feather-degraded metabolites. The results showed that in the presence of degraded metabolites, $21.7 \%$ increase in radicle length and $36.7 \%$ increase in plumule length were observed when compared with control (water only). Also, $5.7 \%$ increase in radicle length and $15.6 \%$ increase in plumule length were observed in the presence of bacterial suspension

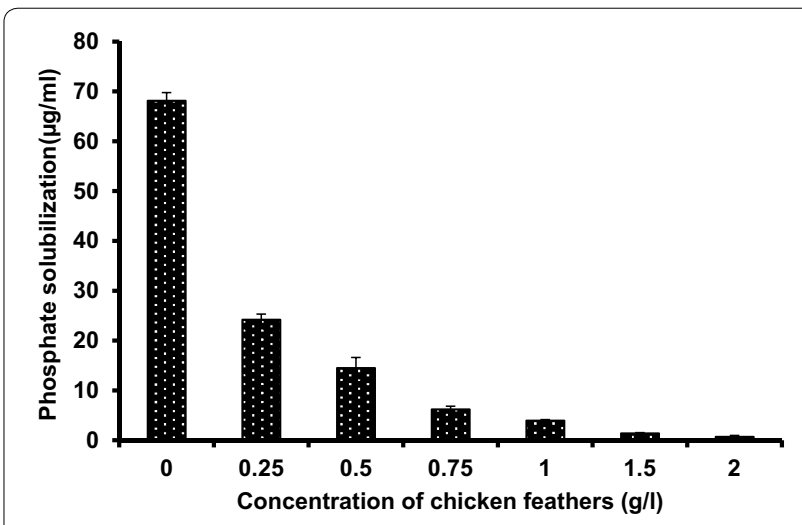

Fig. 4 Phosphate-solubilizing ability of Bacillus subtilis PF1 under the influence of different concentrations of feathers 


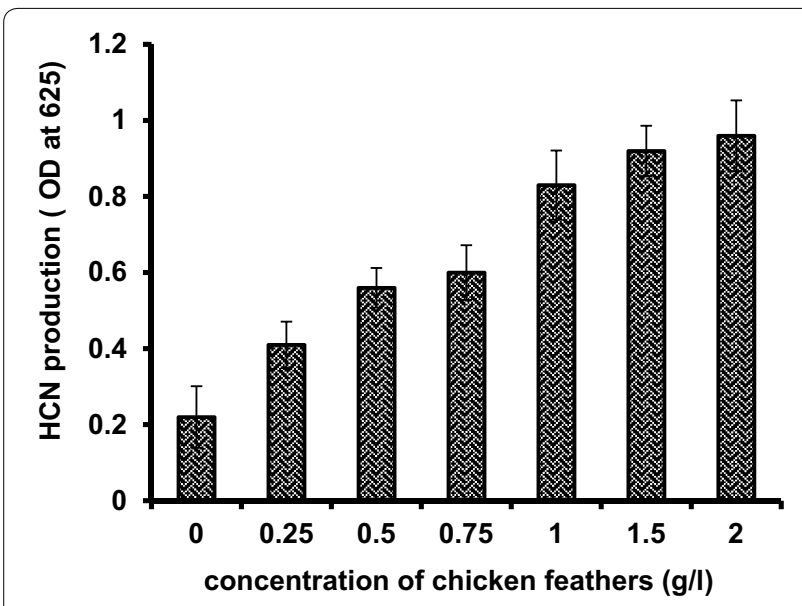

Fig. 5 Production of HCN by Bacillus subtilis PF1 in the presence of different concentrations of feathers. The result is represented as mean \pm standard deviation of three independent variables

containing soil, when compared with control. The results suggest that degraded end products of feather degradation have a beneficial effect on germination and growth of $V$. radiata. It was observed that the presence of degraded metabolites considerably increases the radicle and plumule length.

\section{Chemical analysis of soil samples}

Three sets of pot soil were used for chemical analysis, namely untreated or control (devoid of bacterial suspension and feathers) (S1), soil treated with bacteria suspension (S2) and soil treated with both bacterial suspension and feathers (S3), were analysed after 10 days of incubation. The $\mathrm{pH}$ of the soil treated with both bacterial suspension and feather was found to be slightly increased as compared to control and soil treated with only bacterial suspension due to degradation of feathers. The constituents of necessary elements like C, N, P, K, Ca and

Table 2 Results of plant growth induction study on Vigna radiata

\begin{tabular}{lccc}
\hline Parameters & Control soil & $\begin{array}{l}\text { Soil treated } \\
\text { with bacterial } \\
\text { suspension }\end{array}$ & $\begin{array}{l}\text { Soil treated } \\
\text { with bacterial } \\
\text { suspension } \\
\text { and feathers }\end{array}$ \\
\hline Root length & $5.3 \pm 0.79$ & $6.27 \pm 1.25$ & $9.45 \pm 0.73^{*}$ \\
Root weight (g) & $0.18 \pm 0.02$ & $0.21 \pm 0.11$ & $0.22 \pm 0.17$ \\
Number of root hairs & $5.0 \pm 1.8$ & $7.75 \pm 1.25$ & $10.5 \pm 2.64^{*}$ \\
Plumule length & $6.4 \pm 0.59$ & $8.6 \pm 0.69^{*}$ & $12.8 \pm 0.34^{*}$ \\
Shoot weight & $0.21 \pm 0.007$ & $0.23 \pm 0.009$ & $0.377 \pm 0.05^{*}$ \\
\hline
\end{tabular}

The experiments were performed in triplicate and individual values are depicted as mean \pm standard deviation

* Denotes a value significantly greater than the control value $(p<0.05)$
$\mathrm{Na}$ were altered favourably in $\mathrm{S} 3$. Increased $\mathrm{C} / \mathrm{N}$ ratio and enhanced mineralization in S3 were also observed (Table 3). A significant increase in microbial content was also observed in S3 as compared to other two sets.

\section{Discussion}

India is an agricultural-based developing country where a major portion of population depends on agriculture for their livelihood. Due to growing population and land as a limiting resource, there is a crucial need for increasing productivity of soil. Farmers face huge losses in agriculture due to their inability to purchase high-priced chemical fertilizers. There is a growing need for search of alternate sources of nitrogen-based fertilizers, which are cheap and readily available or readily synthesized. The present study confirms an enhanced plant growthpromoting activity by a keratinolytic bacterium during the degradation of chicken feathers. Fewer reports have emphasized the potential role of degraded feathers in plant growth promotion as the end products of keratin degradation are rich source of nitrogen (Choi and Nelson 1996, Kim et al. 2001).

Keratinolytic bacterial strain $B$. subtilis PF1 was isolated from a feather disposal site and was identified on the basis of $16 \mathrm{~S}$ rDNA analysis. Studies have shown that bacteria from genus Bacillus are known to produce high amounts of enzymes such as keratinase and protease employed for metabolism of protein-containing waste and they also exhibit plant growth-promoting activities. The time course study of feather degradation indicated that the enzyme activity, soluble protein and amino acid concentration reached their highest level at mid to late logarithmic phase of growth. Further incubation declined the proteolytic activity which specified the depletion of medium or feedback inhibition. Similar trend of keratinolysis was observed in previous reports such as in Bacillus cereus MCM B-326 (Nilegaonkar et al. 2007), Bacillus megaterium F7-1 (Park and Son 2009), Bacillus subtilis (Jeong et al. 2010c) and Bacillus cereus (Anwar et al. 2014). Feather degradation potential of Bacillus spp. has been widely reported in previous studies (Lateef et al. 2010, Nilegaonkar et al. 2007, Correa et al. 2010). The time course study of feather degradation by strain PF1 reveals its potential to utilize feather keratin as a sole source of carbon and nitrogen.

Many reports have confirmed that IAA exhibits a pronounced effect on plant growth and development. IAA is responsible for the cell division, cell elongation, cell differentiation and pattern formation in the plants (Dastager et al. 2010). Among the different compounds involved in IAA biosynthesis, L-tryptophan (Trp) and indole (Ind) seem to be good candidates as IAA precursors (Francisco et al. 2005). IAA production has been 


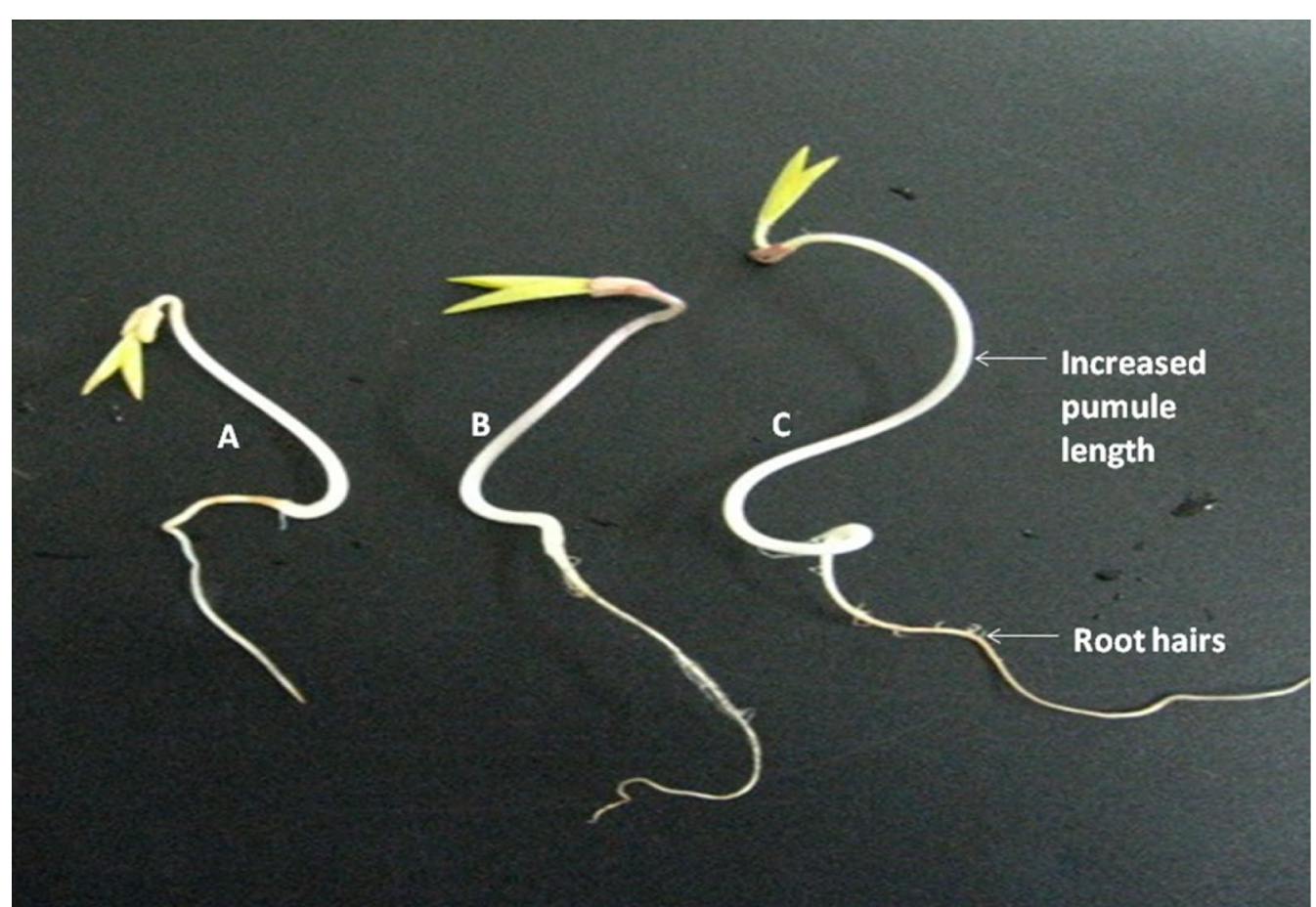

Fig. 6 Inoculation with bacteria and feathers promotes the growth in Vigna radiata: A control, B treated with bacteria and $C$ treated with bacteria and feather

Table 3 Chemical analysis of control (S1), soil treated with bacterial suspension (S2) and soil treated with both bacterial suspension and chicken feathers (S3) after 10 days of incubation

\begin{tabular}{|c|c|c|c|c|c|c|c|c|c|}
\hline Samples & $\mathrm{PH}$ & Total C (\%) & Total N (\%) & $M g$ (ppm) & Ca (ppm) & $\begin{array}{l}\mathrm{P}_{2} \mathrm{O}_{5} \\
\text { (Kg/heq.) }\end{array}$ & $\mathrm{NO}_{3}$ (Kg/heq.) & $\begin{array}{l}\text { Sodium absorp- } \\
\text { tion ratio (SAR) }\end{array}$ & $\mathrm{C} / \mathrm{N}$ ratio \\
\hline S1 & $5.99 \pm 0.08$ & $0.53 \pm 0.033$ & $0.125 \pm 0.06$ & $337.0 \pm 2.1$ & $413.0 \pm 4.61$ & $16.00 \pm 0.43$ & $109.20 \pm 1.80$ & $1.17 \pm 2.7$ & $4.24 \pm 0.21$ \\
\hline S2 & $6.2 \pm 0.12$ & $0.75 \pm 0.062^{*}$ & $0.145 \pm 0.13^{*}$ & $352.0 \pm 5.21^{*}$ & $410.0 \pm 3.15$ & $17.8 \pm 0.81$ & $112.5 \pm 4.0$ & $1.21 \pm 2.01$ & $5.17 \pm 0.70$ \\
\hline S3 & $6.51 \pm 0.05^{*}$ & $1.15 \pm 0.10^{*}$ & $0.178 \pm 0.25^{*}$ & $354.0 \pm 3.71^{*}$ & $424.8 \pm 3.94^{*}$ & $21.3 \pm 1.05^{*}$ & $119.3 \pm 3.89^{*}$ & $1.24 \pm 1.98$ & $6.46 \pm 0.29^{*}$ \\
\hline
\end{tabular}

Total contents of elements were determined and expressed as grams per $1000 \mathrm{~g}$ of soil $(\mathrm{ppm})$, and total C and $\mathrm{N}$ were expressed in (\%), whereas $\mathrm{NO}_{3}, \mathrm{P}_{2} \mathrm{O}_{5}$ and $\mathrm{K}_{2} \mathrm{O}$ were expressed in ( $\mathrm{Kg} / \mathrm{heq}$.). Results are expressed as a mean of 3 individual experiments. The experiments were performed in triplicate and individual values are depicted as mean \pm standard deviation

* Denotes a value significantly greater than the control value $(p<0.05)$

reported by several microorganisms using different precursors such as tryptophan-mediated synthesis of IAA by Pseudomonas fluorescens (Kochar et al. 2011) and indole-3-acetamide-mediated IAA biosynthesis by Fusarium species (Tsavkelova et al. 2012). However, very few reports are available regarding IAA production through feather degradation (Jeong et al. 2010a). The hydrolysis of feathers results in a significant amount of L-tryptophan (Jeong et al. 2010a) and most of the keratinolytic microorganisms having the ability to produce IAA from L-tryptophan. Therefore, keratinolytic microorganisms may offer economical tools for the synthesis of IAA by the successful degradation of chicken feathers. The result has also revealed that the production of IAA was accelerated with the addition of L-tryptophan. Similar pattern of IAA production was obtained by Stenotrophomonas maltophilia R13, Xanthomonas sp. P5 and Bacillus subtilis (Jeong et al. 2010a, b, c). An increased synthesis of IAA was observed with the increasing concentration of chicken feathers. It is due to the fact that during degradation of chicken feathers, tryptophan present in keratin is released into the culture medium which is used by the bacterium to produce IAA (Jeong et al. 2010a). Results of this study confirm that metabolites produced after degradation of chicken feathers can be employed for synthesis of IAA by the bacterium.

The important role of ammonia as a bio-control agent has already been reported (Trivedi et al. 2008). The present study described the production of ammonia during feather hydrolysis by strain PF1. Ammonia production 
has been also reported by Bacillus subtilis isolated from forest soil (Jeong et al. 2010c). Phosphate is abundant in soil and plays a major role in plant growth. The overall phosphate use efficiency following the application of phosphate fertilizer is very low because of the formation of insoluble complexes (Dastager et al. 2010). Phosphate solubilization is another good property of strain PF1, which enhances the uptake of phosphate thereby promoting plant growth for better yield. However, increased concentration of degraded metabolites of chicken feather exhibited a negative effect on phosphate solubilization. This result is supported by the fact that phosphatesolubilizing microorganisms solubilize insoluble form of phosphate by acidification (Kaur and Reddy 2014) and feather-degraded metabolites are alkaline in nature which inhibits phosphate solubilization. This shows that in order to fulfil the phosphate requirement of plants, phosphate should be provided externally when feathers are used as biofertilizers. $\mathrm{HCN}$ indirectly enhances the plant growth by acting as a microbial antagonist and is yet another influential trait of PGPR (Goswami et al. 2014). The present study indicates that the feathers augmented the production of HCN which would be advantageous for eradication of plant pathogens.

$V$. radiata was selected to determine the effect of degraded metabolites of chicken feather. Being an important pulse crop of Fabaceae family (Silva et al. 2013), V. radiata is grown in many tropical and subtropical countries for beneficial health effects (Das and Tiwary 2014). The seeds were selected owing to its short germination time and ease of handling. Degraded metabolites of chicken feathers positively affected the germination of mung bean probably by providing the nitrogen sources. Length and numbers of root hairs increased significantly in feather-digested soil. Increased root length and numbers of root hairs also increase the surface area of root which enhances the absorption of nutrients from soil. This result is comparable with that of Paul et al. (2013) who reported the role of feather hydrolysate in enhancing the number of root hairs. Increased weight of shoot and plumule length revealed the promotion of plant growth. Similar results were also obtained by Anwar et al. (2014), who observed growth promotion in Brassica juncea after inoculation with $B$. cereus. It has been proposed that the feather hydrolysate provides the metabolites required to synthesize the major nutrient and hormones. A slightly increased $\mathrm{pH}$ was observed in soil amended with degraded feather metabolite (S3) as compared to other two sets which indicated the release of ammonia by deamination of peptides and amino acids as reported in Bacillus licheniformis ER-15 (Tiwary and Gupta 2010). Reports have shown that feathers disintegrate slowly and thus act as good sources of slow-release fertilizers (Hadas and Kautsky 1994). Currently, we are studying in situ degradation of raw feathers in soil by this isolate in microcosm-based experiments. We have observed that the direct degradation of feathers in soil by this strain would open a possibility for developing a suitable strategy for removal of feather waste and its bioconversion into fertilizers, which can be supplemented to plants.

\section{Conclusion}

Feather degradation property of B. subtilis PF1 could be efficiently utilized in feather waste management. The metabolites released by feather degradation along with strain PF1 could be successfully employed as an economic source of nitrogen fertilizers for plants. Although the other parameters such as phosphate solubilization and mineralization could positively influence the growth of mung bean seedlings, IAA production by the $B$. subtilis PF1 using chicken feathers is proposed as a major means of attaining growth.

\section{Authors' contributions}

$\mathrm{KB}$ contributed to experimental design, data acquisition, result analysis and manuscript preparation. VC contributed to FTIR interpretation and manuscript preparation. RB contributed to experimental design, data interpretation and manuscript correction. All authors read and approved the final manuscript.

\section{Author details}

${ }^{1}$ Department of Biotechnology, Guru Ghasidas Vishwavidyalaya (A Central University), Bilaspur 495009, Chhattisgarh, India. ${ }^{2}$ School of Biotechnology, Banaras Hindu University, Varanasi, UP, India.

\section{Acknowledgements}

We would like to thank Columbia Institute of Engineering and Technology for FTIR analysis.

\section{Competing interests}

The authors declare that they have no competing interests.

Received: 9 September 2015 Accepted: 2 March 2016

Published online: 14 March 2016

\section{References}

Ahemad M, Kibret M (2014) Mechanisms and applications of plant growth promoting rhizobacteria: current perspective. J King Saud Univ Sci 26:1-20

Anbu P, Gopinath SCB, Hilda A, Lakshmipriya T, Annadurai G (2007) Optimization of extracellular keratinase production by poultry farm isolates Scopulariopsis brevicaulis. Bioresour Technol 98:1298-1303

Anwar MS, Siddique MT, Verma A, Rao YR, Nailwal T, Ansari MW, Pande V (2014) Multitrait plant growth promoting (PGP) rhizobacterial isolates from Brassica juncea rhizosphere. Commun Integr Biol 7:1-9

Castric PA (1974) Hydrogen cyanide; a secondary metabolite of Pseudomonas aeruginosa. Can J Microbiol 21:613-618

Cheng X, Huang L, Tu X, Li K (2010) Medium optimization for the feather degradation by Streptomyces fradiae Var S-221 using the response surface methodology. Biodegradation 21:117-122

Choi JM, Nelson PV (1996) Developing a slow release nitrogen fertilizer from organic sources using poultry feathers. J Am Soc Hortic Sci 121:634-638

Correa APF, Daroit DJ, Brandelli A (2010) Characterization of keratinase produced by Bacillus Sp. P7 isolated from an Amazonian environment. Int Biodeter Biodegr 64:1-6 
Das R, Tiwary BN (2014) Production of indole acetic acid by novel bacterial strain of Planomicrobium chinense isolated from diesel oil contaminated site and its impact on the growth of Vigna radiate. Eur J Soil Biol 62:92-100

Dastager SG, Deepa CK, Pandey A (2010) Isolation and characterization of novel plant growth promoting Micrococcus sp NII-0909 and its interaction with cowpea. Plant Physiol Biochem 48:987-992

De Logu A, Uda P, Pellerano ML, Pouseda ML (2001) Comparison of two rapid calorimetric methods for determining resistance of Mycobacterium tuberculosis to rifampin, isoniazid, streptomycin in liquid medium. Eur J Clin Microbiol 20:33-39

Eaton AD, Lenore SC, Greenberg AE (1995) Standard methods for the examination of water and wastewater, 19th edn. American Public Health Association, Washington DC. ISBN 0875532233

Francisco SS, Houdusse F, Zamarreno AM, Garnica M, Casanova E, Garcia-Mina JM (2005) Effects of IAA and IAA precursors on the development, mineral nutrition, IAA content and free polyamine content of pepper plants cultivated in hydroponic conditions. Sci Hortic (Amsterdam) 106:38-52

Goswami D, Dhandhukia P, Patel P, Thakkar JN (2014) Screening of PGPR from saline desert of Kutch: growth promotion in Arachis hypogia by Bacillus licheniformis A2. Microbiol Res 169:66-75

Hadas A, Kautsky L (1994) Feather meal a semi slow release nitrogen fertilizers for organic farming. Fert Res 38:165-170

Jeong JH, Lee OM, Jeon YD, Kim JD, Lee NR, Lee CY, Son HJ (2010a) Production of keratinolytic enzyme by a newly isolated feather-degrading Stenotrophomonas maltophilia that produces plant growth-promoting activity. Process Biochem 45:1738-1745

Jeong JH, Jeon YD, Lee OM, Kim JD, Lee NR, Park GT, Son HJ (2010b) Characterization of a multifunctional feather-degrading Bacillus subtilis isolated from forest soil. Biodegradation 21:1029-1040

Jeong JH, Park KH, Oh DJ, Hwang DY, Kim HS, Lee CY, Son HJ (2010c) Keratinolytic enzyme-mediated biodegradation of recalcitrant feather by a newly isolated Xanthomonas sp. P5. Polym Degrad Stab 95:1969-1977

Kaur G, Reddy MS (2014) Solubilizing bacteria on crop yield and soil fertility at multilocational site. Eur J Soil Biol 61:35-40

Kim JM, Lim WJ, Suh HJ (2001) Feather degrading Bacillus species from poultry waste. Process Biochem 37:287-291

Kochar M, Upadhyay A, Srivastava S (2011) Indole-3-acetic acid biosynthesis in the biocontrol strain Pseudomonas fluorescens Psd and plant growth regulation by hormone overexpression. Res Microbiol 162:426-435

Kumar P, Dubey RC, Maheshwari DK (2012) Bacillus strains isolated from rhizosphere showed plant growth promoting and antagonistic activity against phytopathogens. Microbiol Res 167(2012):493-499

Lasekan A, Abu Bakar F, Hashim D (2013) Potential of chicken by-products as sources of useful biological resources. Waste Manage 33:552-556

Lateef A, Oloke JK, Gueguim EB, Sobowale BO, Ajao SO, Bello BY (2010) Keratinolytic activities of a new feather- degrading isolate of Bacillus cereus LAU 08 isolated from Nigerian soil. Int Biodeter Biodegr 64:162-165

Mehta S, Nautiyal CS (2001) An efficient method for qualitative screening of phosphate-solubilizing bacteria. Curr Microbiol 43:51-56

Nilegaonkar SS, Zambare VP, Kanekar PP, Dhakephalkar PK, Sarnaik SS (2007) Production and Partial characterization of dehairing protease from Bacillus cereus MCM B-326. Bioresour Technol 98:1238-1245
Nustorova M, Braikova D, Gousterova A, Vasileva-Tonkova E, Nedkov P (2006) Chemical, microbiological and plant analysis of soil fertilized with alkaline hydrolysate of sheep's wool waste, world. J Microbiol Biotechnol 22:383-390

Olsen SR, Sommers LE (1982) Phosphorus. In: Pageetal AL (ed) Methods of soil analysis, part 2 Agron Mongr 9, 2nd edn. ASA and SSSA, Madison, pp 416-418

Park GT, Son HJ (2009) Keratinolytic activity of Bacillus megaterium F7-1 a feather- degrading mesophilic bacterium. Microbiol Res 164:478-485

Paul T, Haldar SK, Das A, Bera S, Maity C, Mandal A, Das PS, Das Mohapatra PKD, Pati BR, Mondal KC (2013) Exploitation of chicken feather waste as a plant growth promoting agent using keratinase producing novel isolate Paenibacillus woosongensis TKB2. Biocatal Agric Biotechnol 2:50-57

Perez-Montano F, Alias-Vilegas C, Bellogin RA, Del Cerro P, Espunny MR, Jimenez- Guerrero I, Lopez Baena FJ, Ollero J, Cubo T (2014) Plant growth promotion in cereal and plant: from microorganism capabilities to crop production. Microbiol Res 169(5-6):325-336

Sachdev DP, Chaudhari HG, Kasture VM, Dhavale DD, Chopade BA (2009) Isolation and characterization of indole acetic acid (IAA) producing Klebsiella pneumoniae strains from rhizosphere of wheat (Triticum aestivum) and their effect on plant growth. Indian J Exp Biol 47:993-1000

Sadasivam S, Mannikkam A (1992) Biochemical methods for agricultural sciences. Wiley Estern Ltd., New Delhi (246)

Senthilkumar M, Swarnlakshmi K, Govindasamy V, Lee YK, Annapurna K (2009) Biocontrol potential of soybean bacterial endophytes against charcoal rot fungus Rhizoctonia bataticola. Curr Microbiol 58:288-293

Silva LR, Pereira MJ, Rui JA, Gonçalves F, Valentão P, Guedes de Pinho P, Andrade PB (2013) Glycine max (L.) Merr. Vigna radiata L. and Medicago sativa L. sprouts: a natural source of bioactive compounds. Food Res Int 50:127-175

Sunar K, Dey P, Chakraborty U, Chakraborty B (2013) Biocontrol efficacy and plant growth promoting activity of Bacillus altitudinis isolated from Darjeeling hills. India J Basic Microbiol 55:91-104

Tatineni R, Doddapaneni KK, Potumarthi RC, Vellanki RN, Kandathil MT, Kolli N, Mangamoori LN (2008) Purification and characterization of an alkaline keratinase from Streptomyces sp. Bioresour Technol 99:1596-1602

Tiwary E, Gupta R (2010) Medium optimization for a novel 58 kDa dimeric keratinase from Bacillus licheniformis ER-15; biochemical characterization and application in feather degradation and dehairing of hides. Bioresour Technol 101:6103-6110

Trivedi P, Pandy A, Palni LM (2008) In vitro evaluation of antagonistic properties of Pseudomonas corrugate. Microbiol Res 163:329-336

Tsavkelova E, Oeser B, Oren-Young L, Israeli M, Sasson Y, Tudzynski B, Sharon A (2012) Identification and functional characterization of indole-3-acetamide mediated IAA biosynthesis in plant associated Fusarium species. Fungal Genet Biolol 49:48-57

Verma JP, Yadav J, Tiwary KN, Jaiswal DK (2013) Evaluation of plant growth promoting activities of microbial strains and their effect on growth and yield of chickpea (Cicer arietinum) in India. Soil Biol Biochem 70:33-37

Vessey JK (2003) Plant growth promoting rhizobacteria as biofertilizers. Plant Soil 255:571-586

\section{Submit your manuscript to a SpringerOpen ${ }^{\circ}$ journal and benefit from:}

- Convenient online submission

- Rigorous peer review

- Immediate publication on acceptance

- Open access: articles freely available online

- High visibility within the field

- Retaining the copyright to your article

Submit your next manuscript at springeropen.com 